\title{
Single double-lumen venous-venous pump-driven extracorporeal lung membrane support
}

\author{
David Sanchez-Lorente, MD, ${ }^{\text {a }}$ Tetsuhiko Go, MD, ${ }^{a}$ Philipp Jungebluth, MD, ${ }^{\mathrm{a}}$ Irene Rovira, MD, \\ Maite Mata, RN, ${ }^{\mathrm{a}}$ Maria Carme Ayats, $\mathrm{RN},{ }^{\mathrm{a}}$ and Paolo Macchiarini, MD, $\mathrm{PhD}^{\mathrm{a}, \mathrm{c}, \mathrm{d}}$
}

Objective: We sought to investigate the safety and feasibility of obtaining total respiratory support during 72 hours using a pump-driven (Levitronix CentriMag; Levitronix LLC, Waltham, Mass) venous-venous extracorporeal lung membrane (Novalung; Novalung GmbH, Hechingen, Germany) attached through a single doublelumen cannula (Novalung) into the femoral or jugular vein in pigs.

\begin{abstract}
Methods: Twelve pigs were initially mechanically ventilated for 2 hours (respiratory rate, 20-25 breaths/min; tidal volume, $10-12 \mathrm{~mL} / \mathrm{kg}$; fraction of inspired oxygen, 1.0 ; positive end-expiratory pressure, $5 \mathrm{~cm} \mathrm{H}_{2} \mathrm{O}$ ). Thereafter, the extracorporeal lung membrane was attached to the right femoral $(n=6,26 \mathrm{~F})$ or jugular $(n=6,22 \mathrm{~F})$ vein by using a single double-lumen cannula placed transcutaneously. Ventilatory settings were then reduced to nearapneic ventilation (respiratory rate, 4 breaths $/ \mathrm{min}$; tidal volume, $1-2 \mathrm{~mL} / \mathrm{kg}$; fraction of inspired oxygen, 0.21 ; positive end-expiratory pressure, $10 \mathrm{~cm} \mathrm{H}_{2} \mathrm{O}$ ), and pump flow was increased hourly until maximal efficacy. Blood gases and hemodynamics were measured hourly, and lung and plasma cytokine levels were measured every 4 hours.
\end{abstract}

Results: The device's mean blood flow was $2.16 \pm 0.43 \mathrm{~L} / \mathrm{min}$, permitting an oxygen transfer and carbon dioxide removal of $203.6 \pm 54.6$ and $590.3 \pm 23.3 \mathrm{~mL} / \mathrm{min}$, respectively. Despite static ventilation, all pigs showed optimal respiratory support, with a $\mathrm{PaO}_{2}, \mathrm{PaCO}_{2}$, and mixed venous oxygen saturation of $226.2 \pm 56.4,59.7 \pm 8.8$, and $85.6 \pm 5.3 \mathrm{~mm} \mathrm{Hg}$, respectively. There were no significant inflammatory, cellular, or coagulatory responses; lung cytokine levels remained in the normal range. Route (femoral vs jugular) or size ( $22 \mathrm{~F} \mathrm{vs} 26 \mathrm{~F}$ ) of the cannula did not change hemodynamic or respiratory parameters significantly.

Conclusions: This circuit provides total respiratory support over 72 hours without inducing significant hemodynamic, coagulatory, cellular, or inflammatory responses. (J Thorac Cardiovasc Surg 2010;140:558-63)

Supplemental material is available online.

Video clip is available online.

In contrast to advances in the development of cardiac support systems for adults, the development of extracorporeal

\footnotetext{
From the General Thoracic Surgical Experimental Laboratory ${ }^{\mathrm{a}}$ and Department of Aneshesiology, ${ }^{b}$ Hospital Clínic, University of Barcelona; Fundació Clínic ${ }^{c}$; and Institut d'Investigacions Biomèdiques Augut Pi i Sunyer (IDIBAPS), ${ }^{\mathrm{d}}$ Barcelona, Spain.

Disclosures: None.

Read at the Eighty-ninth Annual Meeting of The American Association for Thoracic Surgery, Boston, Mass, May 9-13, 2009

Received for publication May 22, 2009; revisions received Nov 8, 2009; accepted for publication Dec 12, 2009

Address for reprints: Paolo Macchiarini, MD, PhD, Department of General and Regenerative Surgery and Intrathoracic Biotransplantation, University Hospital Careggi, Largo Brambilla 3, I-50139 Florence, Italy (E-mail: pmacchiarini@thoraxeuropea.eu). $0022-5223 / \$ 36.00$

Copyright $₫ 2010$ Published by Elsevier Inc. on behalf of The American Association for Thoracic Surgery

doi:10.1016/j.jtcvs.2009.12.057
}

mechanical systems for failing lungs has lagged far behind. Novalung (Novalung GmbH, Hechingen, Germany) is a pumpless extracorporeal respiratory assist device including a low-resistance heparin-bonded membrane that, once attached to the femoral vessels, allows an arterial-venous gas exchange with the cardiac pump as the driving force. The membrane removes almost all carbon dioxide, and this in turn permits the reduction of the mechanical ventilator settings beyond the ARDSnet guidelines, thus minimizing ventilator-induced lung injury and giving the native lungs time to heal. ${ }^{1-6}$ Unfortunately, because of the low driving blood flow (1-2 L/min) perfusing the device, oxygenation is limited, and evidence now exists that distal perfusion of the cannulated limbs represents a clinical issue.

To improve this and because profound hypoxemia might become the prominent indication of extracorporeal support for high-mortality-risk respiratory failure, we investigated whether a single double-lumen venous cannula and magnetic centrifuged pump (Levitronix CentriMag Blood Pump; Levitronix LLC, Waltham, Mass) ${ }^{7}$ coupled with the Novalung device would provide complete respiratory support in a healthy pig model and determined the magnitude of its inflammatory, blood cell trauma coagulation response. 


$$
\begin{aligned}
& \text { Abbreviations and Acronyms } \\
& \text { ACT = activated clotting time } \\
& \mathrm{BAL}=\text { bronchoalveolar lavage } \\
& \mathrm{CaO}_{2}=\text { oxygen content } \\
& \mathrm{ECMO}=\text { extracorporeal membrane oxygenation } \\
& \mathrm{FIO}_{2}=\text { fraction of inspired oxygen } \\
& \text { IL = interleukin } \\
& \text { PEEP = positive end-expiratory pressure } \\
& \text { PIP = peak inspiratory pressure } \\
& \mathrm{RR} \quad=\text { respiratory rate } \\
& \mathrm{V}_{\mathrm{T}} \quad=\text { tidal volume }
\end{aligned}
$$

\section{MATERIALS AND METHODS}

Twelve Yorkshire Duroc pigs (Isoquimen S/L, Barcelona, Spain) weighing $59.3 \pm 6.18 \mathrm{~kg}$ were used. All animals received care in compliance with the "Principles of Laboratory Animal Care" formulated by the National Society for Medical Research and the "Guide for the Care and Use of Laboratory Animals" prepared by the Institute of Laboratory Animal Resources, National Research Council and published by the National Academy Press (revised 1996). The study was approved by the Institutional Animal Care and Use Committee of the University of Barcelona, with strict adherence to the Institutional Animal Care and Use Committee guidelines regarding humane use of animals (project N-001-61399030-F).

\section{Study Design}

The study working plan is depicted in Figure E1. Animals were intubated and initially underwent volume-controlled ventilation (respiratory rate [RR], 20 breaths $/ \mathrm{min}$; tidal volume $\left[\mathrm{V}_{\mathrm{T}}\right], 10 \mathrm{~mL} / \mathrm{kg}$; fraction of inspired oxygen [ $\mathrm{FIO}_{2}$ ], 1.0; and positive end-expiratory pressure [PEEP], $5 \mathrm{~cm} \mathrm{H}_{2} \mathrm{O}$ ) with a mechanical ventilator (Servo 900D; Siemens, Munich, Germany) followed by 2 hours of stabilization. Animals were then randomly assigned to cannulation either through the femoral $(n=6)$ or jugular $(n=6)$ veins through the double-lumen caval cannula (see Figure E2) connected with the Novalung membrane and the Levitronix CentriMag pump (see Figure E3 and Video E1). Starting with a minimal $(0.1-0.2 \mathrm{~L} / \mathrm{min})$ pump flow, the ventilator settings were reduced to reach near-static or near-apneic ventilator settings (RR, $\leq 4$ breaths/min; VT, $1-2 \mathrm{~mL} / \mathrm{kg}$; $\mathrm{FIO}_{2}, 0.21$; PEEP, $10 \mathrm{~cm} \mathrm{H}_{2} \mathrm{O}$ ) and thereby permissive hypercapnia. Once reached, the pump blood flows were increased by $0.5 \mathrm{~L} / \mathrm{min}$ continuously to reach $2 \mathrm{~L} / \mathrm{min}$, which was sufficient in our preliminary experience to provide complete gas exchange. Pump flow was increased thereafter in a stepwise fashion at 1-hour intervals to reach the most efficient flow for the most effective gas exchange (exploratory phase). Animals were then monitored to examine the physiological and biological influence of the system for a total of 72 hours (monitoring phase).

A real-time flowmeter (Novalung $\mathrm{GmbH}$ ) measured the extracorporeal flow through the device by using an ultrasonic flow probe (Sono TT ultrasonic flowmeter; Emtech GmbH, Finning, Germany). Device malfunction was defined by the occurrence of a blood flow of less than $0.5 \mathrm{~L} / \mathrm{min}$ or if a $50 \%$ blood flow reduction was noted. Activated clotting time (ACT) was maintained at approximately 180 to 200 seconds (an alternative was an activated partial thromboplastin time of 50-60 seconds) by using a continuous heparin infusion and checked every 2 hours. Excessive bleeding or low blood flow caused by malposition of the cannula required reintervention. The capability of the device to provide additional oxygen was measured by calculating the oxygen content $\left(\mathrm{CaO}_{2}\right)$ of blood entering and exiting the Novalung iLA membrane and multiplying the difference by the flow rate through the device, according to the following formulas: $\mathrm{CaO}_{2}=\left(\right.$ Hemoglobin $\left.\times 1.31 \times \mathrm{SaO}_{2}\right)+\left(\mathrm{PaO}_{2} \times 0.003\right) ;$ Oxygen transfer
$(\mathrm{mL} / \mathrm{min})=\left[\mathrm{CaO}_{2}\right.$ after $\mathrm{iLA}-\mathrm{CaO}_{2}$ before iLA $) \times$ Device flow rate $(\mathrm{L} / \mathrm{min}) \times 10$. The arteriovenous extracorporeal carbon dioxide removal $\left(\mathrm{AVCO}_{2} \mathrm{R}\right)$ provided by the device was calculated as follows: $\mathrm{AVCO}_{2} \mathrm{R}$ $(\mathrm{mL} / \mathrm{min})=\mathrm{CO}_{2}$ content in the inflow cannula $-\mathrm{CO}_{2}$ content in the outflow cannula $(\mathrm{mL} \mathrm{CO} 2 / \mathrm{mL}$ blood $) \times$ Blood flow iLA $(\mathrm{L} / \mathrm{min}) \times 10.5$.

During the exploratory phase, respiratory parameters and hemodynamics (through a Swan-Ganz catheter) were registered hourly, as were hematologic parameters. Biological values (cytokines in blood plasma and bronchoalveolar lavage [BAL] fluid) were registered at the moment of intubation and placement of the artificial lung system and then 6 hours after intubation of the pig. During the monitoring phase, all parameters were measured and recorded every 4 hours, and biological parameters were measured every 12 hours. All data measured before initiation of the extracorporeal support were set as baseline values.

\section{Anesthesia and Monitoring}

Yorkshire Duroc pigs were received and quarantined for at least 1 week before the operation. Selection was based on results of physical examinations and body weight. Animals were premedicated with azaperone as a sedative $(4 \mathrm{mg} / \mathrm{kg}$ administered intramuscularly) and thiopental as a hypnotic $(10 \mathrm{mg} / \mathrm{kg}$ administered intravenously; B. Braun, Medical S.A., Rubi, Barcelona, Spain) through ear veins. Animals were placed on the surgical table in the supine position, and induction anesthesia was performed with propofol (Diprivan, AstraZeneca, Wilmington, Del), $5 \mathrm{mg} / \mathrm{kg}$ administered intravenously, and fentanyl (Fentanest; Kern Pharma, Barcelona, Spain), $5 \mu \mathrm{g} / \mathrm{kg}$ administered intravenously. For relaxation, $6 \mathrm{mg} \cdot \mathrm{kg}^{-1} \cdot \mathrm{h}^{-1}$ of rocuronium bromide (Esmeron; Schering-Plough, Kenilworth, NJ) was administered intravenously. Animals were intubated orotracheally with a $7.5 \mathrm{~F}$ endotracheal tube and mechanically ventilated with insertion of a nasogastric tube. Anesthesia was maintained with continuous endovenous infusion of fentanyl $\left(1 \mu \mathrm{g} \cdot \mathrm{kg}^{-1} \cdot \mathrm{h}^{-1}\right)$ and propofol $\left(3-5 \mathrm{mg} \cdot \mathrm{kg}^{-1} \cdot \mathrm{h}^{-1}\right)$ until the study's end. At the time of instrumentation, intravenous cefazolin $(1 \mathrm{~g})$ was administered and then every 3 hours thereafter. Inotropic and vasoactive drugs (noradrenaline, $4 \mathrm{mg}$ in $250 \mathrm{~mL}$ of $5 \%$ glucosaline solution at $5 \mathrm{~mL} / \mathrm{h}$ administered intravenously) were used if necessary. A loading dose of heparin was administered before the single double-lumen cannula insertion $(150 \mathrm{IU} / \mathrm{kg}$ ) and every 2 hours $(50 \mathrm{U} / \mathrm{kg})$ thereafter to prevent vessel clotting (targeting activated partial thromboplastin time, 50-60; ACT, 180-200).

Fluid management was standardized by using continuous infusion of $0.9 \% \mathrm{NaCl}$ at a rate of $100 \mathrm{~mL} / \mathrm{h}$ with the following exceptions. First, if mean arterial pressure was less than $60 \mathrm{~mm} \mathrm{Hg}$ or central venous pressure was less than $8 \mathrm{~mm} \mathrm{Hg}$, an additional $100 \mathrm{~mL}$ of colloid solution was infused over 1 minute. Second, if central venous pressure was greater than $10 \mathrm{~mm} \mathrm{Hg}$, the continuous infusion was stopped until it returned to within the goal range of 8 to $10 \mathrm{~mm} \mathrm{Hg}$. Atropine ( $0.5-1 \mathrm{mg}$ administered intravenously) was administrated if cardiac frequency was less than 50 beats per minute.

Animals were initially mechanically ventilated with the following settings, followed by 2 hours of stabilization: $\mathrm{V}_{\mathrm{T}}$ of $10 \mathrm{~mL} / \mathrm{kg}$, minute volume of $11 \mathrm{~L} / \mathrm{min}, \mathrm{RR}$ of 20 breaths/min, peak inspiratory pressure (PIP) of $30 \mathrm{~cm}$ $\mathrm{H}_{2} \mathrm{O}$ or less, $\mathrm{FIO}_{2}$ of 1.0, and PEEP of $5 \mathrm{~cm} \mathrm{H}_{2} \mathrm{O}$. After stabilization, the double-lumen cannula was inserted, and the Novalung with the Levitronix CentriMag Blood Pump system was attached at a flow level of 0.1 to $0.2 \mathrm{~L} /$ min for 30 minutes. Thereafter, the ventilator settings were reduced gradually to reach static or passive ventilator settings: RR, 4 or fewer breaths $/ \mathrm{min}$, confirming a PIP of less than $15 \mathrm{~cm} \mathrm{H}_{2} \mathrm{O} ; \mathrm{V}_{\mathrm{T}}, 1$ to $2 \mathrm{~mL} / \mathrm{kg} ; \mathrm{FIO}_{2}, 0.21$; and PEEP, $10 \mathrm{~cm} \mathrm{H}_{2} \mathrm{O}$. During the 2-hour stabilization period, measurement catheters were inserted, and blood samples were taken.

\section{Respiratory Parameters and Hemodynamics}

Respiratory parameters. The following parameters were recorded hourly until the best blood pump flow was decided, and afterward, parameters were recorded every 4 hours. Ventilator settings were as follows: $V_{T}$ (in milliliters per kilogram), minute volume (in liters per minute), PEEP 
(in centimeters of $\mathrm{H}_{2} \mathrm{O}$ ), $\mathrm{RR}$ (in breaths/min), $\mathrm{PIP}$ (in centimeters of $\mathrm{H}_{2} \mathrm{O}$ ), and $\mathrm{FIO}_{2}$. Gas exchange was as follows: $\mathrm{PaO}_{2}$ (in millimeters of mercury), $\mathrm{PaCO}_{2}$ (in millimeters of mercury), $\mathrm{CaO}_{2}$ (in milliliters per deciliter), content of carbon dioxide (in milliliters per deciliter), $\mathrm{pH}$, alveolar-arterial oxygen difference $\left(\mathrm{DA}-\mathrm{aO}_{2}\right), \mathrm{PaO}_{2} / \mathrm{FIO}_{2}$, end-tidal carbon dioxide, oxygen consumption, oxygen delivery, intrapulmonary shunt or venous admixture, mixed venous oxygen content, mixed venous carbon dioxide content, and ventilatory efficiency index. Mechanical respiratory function was determined as follows: static respiratory system compliance, chest wall compliance, and lung compliance.

Hemodynamic parameters. All animals were instrumented with an arterial pressure line $(5 \mathrm{~F})$ placed transcutaneously in the left femoral artery, multiple peripheral venous catheters, and a Swan-Ganz catheter (Edwards Lifesciences, Munich, Germany). The following hemodynamic variables were monitored (Hewlett Packard model 685): heart rate (in beats per minute); cardiac output (in liters per minute); cardiac index (in liters per minute per square meter); systolic, diastolic, and mean arterial pressure (in millimeters of mercury); systolic, diastolic, and mean pulmonary artery pressure (in millimeters of mercury); pulmonary capillary wedge pressure (in millimeters of mercury); central venous pressure (in millimeters of mercury); systolic index (in milliliters per square meter); systolic volume (in milliliters); systemic vascular resistance (Dynes [DS] $\mathrm{cm}^{2}$ )/index systemic vascular resistance (DS $\left.\mathrm{m}^{2} / \mathrm{cm}^{2}\right)$; vascular pulmonary resistance $\left(\mathrm{DS} / \mathrm{cm}^{2}\right) /$ index vascular pulmonary resistance (DS $\left.\mathrm{m}^{2} / \mathrm{cm}^{2}\right)$; left ventricular stroke work/index (in $[\mathrm{g}-\mathrm{m}] /\left[\mathrm{g}-\mathrm{m} / \mathrm{m}^{2}\right]$ ); and right ventricular stroke work/index (in $[\mathrm{g}-\mathrm{m}] /\left[\mathrm{g}-\mathrm{m} / \mathrm{m}^{2}\right]$ ). Body temperature (in degrees Celsius) was measured with a Swan-Ganz catheter and was maintained at $37^{\circ} \mathrm{C}$ with a heater and blankets. A pulse oximeter (BCI, Inc, Waukesha, Wis), placed on the pig's tail, measured peripheral arterial saturation as a percentage. Urine output was monitored with a percutaneous bladder catheter.

\section{Evaluation of Blood Cell Trauma, Coagulation, and Inflammatory Response}

For evaluation of hemolysis, lactate dehydrogenase, potassium, and haptoglobin were controlled every 4 hours. Hemotologic parameters, arterial blood gases, hematocrit, hemoglobin, leukocyte and thrombocyte counts, $\mathrm{Na}, \mathrm{Cl}$, complete blood count, and ACT were evaluated in the same manner. The values of interleukin (IL) $1 \beta$, IL-6, IL-8, IL-6 receptor, and tumor necrosis factor $\alpha$ were measured by means of BAL and plasma samples to evaluate systemic and pulmonary inflammatory responses. BAL samples were taken in sterile conditions with $50 \mathrm{~mL}$ of normal saline. The first BAL was performed after intubation and before starting mechanical ventilation. The second and third BAL samples were obtained during installation of the extracorporeal lung assist device and 6 hours afterward, and thereafter, BAL sample were taken every 12 hours. Blood samples to identify cytokines were taken in the same manner. Blood and BAL samples were centrifuged between 2000 and $3000 \mathrm{rpm}$ for 15 minutes and stored at $-70^{\circ} \mathrm{C}$.

\section{Postmortem Analysis}

After 72 hours of observation, animals were killed immediately at the minimum vital distress in deep sedation. Before euthanasia, heparin (100 $\mathrm{IU} / \mathrm{kg}$ ) was administered to avoid postmortem thrombus formation. Euthanasia was induced with an overdose of potassium chloride $(40 \mathrm{mEq}$ by means of rapid intravenous administration). At autopsy, the heart and the lung were removed to evaluate the presence of emboli or thrombi and structural heart abnormalities or grade of inflammation in the lung. Any gross pathologic findings were photographed and documented.

The lung and heart tissue samples were fixed in $10 \%$ formol, sent to the department of histopathology, and embedded in paraffin after routine follow-up procedures. Vessels with grafts were checked for signals of revascularization in the graft or evidence of emboli or thrombi in cannulated vessels. All devices were evaluated for infection and mechanical properties.
TABLE 1. Pigs' mechanical ventilatory settings and hemodynamic data during initial ventilation ( 2 hours) and apneic ventilation under extracorporeal support (72 hours)

\begin{tabular}{lccc}
\hline & $\begin{array}{c}\text { Initial ventilation } \\
\text { without } \\
\text { extracorporeal } \\
\text { Support }\end{array}$ & $\begin{array}{c}\text { Apneic ventilation } \\
\text { with extracorporeal } \\
\text { support }\end{array}$ & $\begin{array}{c}\boldsymbol{P} \\
\text { value }\end{array}$ \\
\hline $\mathrm{V}_{\mathrm{T}}(\mathrm{mL})$ & $537 \pm 68$ & $115 \pm 13$ & .05 \\
$\mathrm{RR}(\mathrm{breaths} / \mathrm{min})$ & $20 \pm 0$ & $4 \pm 0$ & .05 \\
$\mathrm{MV}(\mathrm{L} / \mathrm{min})$ & $10.7 \pm 1.4$ & $0.4 \pm 0.05$ & .05 \\
$\mathrm{CI}\left(\mathrm{L} \cdot \mathrm{min}^{-1} \cdot \mathrm{m}^{-2}\right)$ & $4.8 \pm 0.6$ & $5.1 \pm 0.9$ & $\mathrm{NS}$ \\
$\mathrm{MAP}(\mathrm{mm} \mathrm{Hg})$ & $113 \pm 9.9$ & $95.4 \pm 12.6$ & $\mathrm{NS}$ \\
$\mathrm{MPAP}(\mathrm{mm} \mathrm{Hg})$ & $24 \pm 5.7$ & $34.4 \pm 3.1$ & $\mathrm{NS}$ \\
$\mathrm{SVR}\left(\mathrm{dyne} / \mathrm{cm}^{5}\right)$ & $872 \pm 252.4$ & $1073 \pm 273.2$ & $\mathrm{NS}$ \\
$\mathrm{PVR}\left(\mathrm{dyne} / \mathrm{cm}^{5}\right)$ & $120.8 \pm 14.3$ & $188 \pm 40.6$ & $\mathrm{NS}$ \\
$\mathrm{PCWP}(\mathrm{mm} \mathrm{Hg})$ & $15.3 \pm 1.75$ & $16.9 \pm 2.4$ & $\mathrm{NS}$ \\
$\mathrm{CVP}(\mathrm{mm} \mathrm{Hg})$ & $11.5 \pm 2.3$ & $12.4 \pm 2.5$ & $\mathrm{NS}$ \\
\hline$V_{T}, \mathrm{Tid}$ & &
\end{tabular}

$V_{T}$, Tidal volume; $R R$, respiratory rate; $M V$, minute volume; $C I$, cardiac index; $N S$, not significant; $M A P$, mean arterial pressure; $M P A P$, mean pulmonary arterial pressure; $S V R$, systemic vascular resistance; $P V R$, pulmonary vascular resistance; $P C W P$, pulmonary capillary wedge pressure; $C V P$, central venous pressure.

\section{Statistical Analysis}

All data were reported as means \pm standard deviations. Data were double entered and checked with an SPSS-12 program (SPSS, Inc, Chicago, Ill). Means, proportions, standard deviations, and 95\% confidence intervals were calculated from every study variable. Parameters were statistically analyzed by means of 1-way analysis of variance for repeated measures to compare values with baseline. Odds ratio were calculated, with a 2-tailed $P$ value of .05, to compare categorical variables. Analysis used the statistical package SPSS-12.

\section{RESULTS}

All animals completed the study protocol, and all cannulations were made with Seldinger's technique. The mean blood flow through the lung membrane was $2.16 \pm 0.43$ L/min. All pigs showed optimal respiratory support during the study period, despite static ventilation, with mean $\mathrm{PaO}_{2}, \mathrm{PaCO}_{2}$, and mixed venous oxygen saturation values of $226.2 \pm 56.4,59.7 \pm 8.8$, and $85.6 \pm 0.3 \mathrm{~mm} \mathrm{Hg}$, respectively. There was no vasoactive drug requirement to maintain hemodynamic stability (Table 1). The device allowed a mean oxygen transfer and carbon dioxide removal of $203.6 \pm 54.6 \mathrm{~mL} / \mathrm{min}$ and $590.3 \pm 23.3 \mathrm{~mL} / \mathrm{min}$, respectively (Figure 1). There were no significant differences in outcome between femoral and jugular cannulation or between cannula sizes (Table 2).

Animals did not have any significant cellular trauma or coagulatory alteration over the 72 hours (Table 3). Figures 2 and 3 show the evolution of lung and plasma cytokine levels during the study, and no significant changes were found during the study. Finally, results of pathological examinations were normal in all specimens, and microbiological evaluation of the circuits was negative. Evaluation of all devices after the study's end did not show any protein leak across the membrane. 


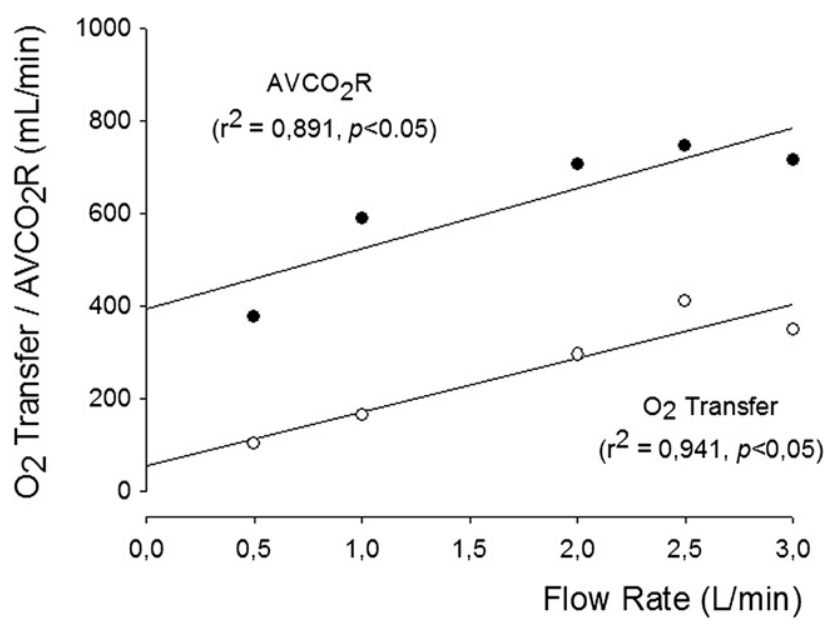

FIGURE 1. Correlation between oxygen transfer and carbon dioxide removal $\left(\mathrm{CO}_{2} \mathrm{R}\right)$ and blood flow perfusing the interventional lung assist device during apneic ventilation $(A V)$.

\section{DISCUSSION}

Developments of new mechanical circulatory support devices in the last decades have allowed an improvement in the prognosis of patients with acute or chronic respiratory failure. Extracorporeal membrane oxygenation (ECMO) is the most known extracorporeal system used thus far and provides both cardiac and respiratory support for severely diseased patients. The venous-venous ECMO does not provide cardiac support but does provide sufficient oxygenation for several weeks, allowing diseased lungs to heal while any potential additional injury of mechanical ventilation is avoided. It has become the standard treatment of respiratory failure in newborn and pediatric patients who do not respond to conventional therapy, but because of the high technical demands, perceived cost, and risk of compli-

TABLE 2. Hemodynamic and respiratory parameter comparisons between jugular vein cannulation and femoral vein cannulation

\begin{tabular}{|c|c|c|c|}
\hline Variables & $\begin{array}{l}\text { Jugular vein } \\
\text { (22F cannula) }\end{array}$ & $\begin{array}{l}\text { Femoral vein } \\
\text { (26F cannula) }\end{array}$ & $P$ value \\
\hline $\mathrm{V}_{\mathrm{T}} \mathrm{a}(\mathrm{mL})$ & $113 \pm 16$ & $116 \pm 13$ & NS \\
\hline RRa (breaths/min) & $4 \pm 0$ & $4 \pm 0$ & NS \\
\hline $\mathrm{MVa}$ (L/min) & $0.45 \pm 0.05$ & $0.46 \pm 0.05$ & NS \\
\hline Flow $_{M}(\mathrm{~L} / \mathrm{min})$ & $2.13 \pm 0.50$ & $2.19 \pm 0.32$ & NS \\
\hline $\mathrm{CI}\left(\mathrm{L} \cdot \min ^{-1} \cdot \mathrm{m}^{-2}\right)$ & $5.15 \pm 0.67$ & $5.19 \pm 1.14$ & NS \\
\hline MAP (mm Hg) & $93.52 \pm 13.22$ & $97.90 \pm 11.45$ & NS \\
\hline MPAP (mm Hg) & $34.63 \pm 3.73$ & $34.15 \pm 2.25$ & NS \\
\hline SVR (dyne/cm ${ }^{5}$ ) & $1001 \pm 214.6$ & $1140 \pm 246.5$ & NS \\
\hline PVR (dyne/cm ${ }^{5}$ ) & $174.77 \pm 38.43$ & $200.81 \pm 37.64$ & NS \\
\hline PCWP $(\mathrm{mm} \mathrm{Hg})$ & $17.28 \pm 2.08$ & $16.54 \pm 2.67$ & NS \\
\hline $\mathrm{CVP}(\mathrm{mm} \mathrm{Hg})$ & $12.93 \pm 2.38$ & $11.77 \pm 2.54$ & NS \\
\hline
\end{tabular}

$V_{T} a$, Tidal volume in apneic ventilation; $N S$, not significant; $R R a$, respiratory rate in apneic ventilation; $M V a$, minute volume in apneic ventilation; Flow $w_{M}$, mean blood flow; $C I$, cardiac index; $M A P$, mean arterial pressure; $M P A P$, mean pulmonary arterial pressure; $S V R$, systemic vascular resistance; $P V R$, pulmonary vascular resistance; $P C W P$, pulmonary capillary wedge pressure; $C V P$, central venous pressure.
TABLE 3. Cellular trauma and coagulatory evaluation without and with extracorporeal support

\begin{tabular}{lccc}
\hline \multicolumn{1}{c}{ Variables } & $\begin{array}{c}\text { Without } \\
\text { extracorporeal } \\
\text { support }\end{array}$ & $\begin{array}{c}\text { With } \\
\text { extracorporeal } \\
\text { support }\end{array}$ & $\boldsymbol{P}$ value \\
\hline $\mathrm{LDH}(\mathrm{IU} / \mathrm{L})$ & $1001 \pm 190.2$ & $881.93 \pm 196.99$ & $\mathrm{NS}$ \\
$\mathrm{K}^{+}(\mathrm{mEq} / \mathrm{L})$ & $3.86 \pm 0.26$ & $3.82 \pm 0.56$ & $\mathrm{NS}$ \\
Haptoglobin $(\mathrm{g} / \mathrm{L})$ & $0.20 \pm 0.092$ & $0.22 \pm 0.094$ & $\mathrm{NS}$ \\
Hemoglobin $(\mathrm{g} / \mathrm{L})$ & $83.16 \pm 8.72$ & $75.53 \pm 10.14$ & $\mathrm{NS}$ \\
Hematocrit $(\mathrm{L} / \mathrm{L})$ & $0.27 \pm 0.04$ & $0.25 \pm 0.03$ & $\mathrm{NS}$ \\
PT $(\mathrm{s})$ & $11.74 \pm 1.89$ & $11.71 \pm 1.50$ & $\mathrm{NS}$ \\
\hline
\end{tabular}

Data express the mean values of the different time scales measured in the 2 groups. $L D H$, Lactate dehydrogenase; $N S$, not significant; $K^{+}$, potassium; $P T$, prothrombin time.

cations (eg, bleeding), ECMO has been less successful in adults. ${ }^{89-11}$

The Novalung iLA device is a relatively new, commercially available, low-resistance-membrane lung with tight diffusion membranes and a protein matrix coating incorporating a gas exchange surface of $1.3 \mathrm{~m}^{2}$. This device has been used successfully to allow and optimize advanced lung-protective ventilation strategies beyond ARDSnet ${ }^{12}$ in an arteriovenous pumpless way in patients with adult respiratory distress syndrome ${ }^{4,13}$ and carbon dioxide retention syndromes without ventilator-associated lung injury in recovery from lung injuries and as a bridge to transplantation. $^{6,14,15}$ The minimal oxygen transfer is an obvious limitation of the pumpless arteriovenous attachment mode. ${ }^{16,17}$ Ischemia of a lower limb caused by femoral arterial cannulation is another concern, being the most common complication $(5.9 \%$ to $11 \%)$ of the iLA device. ${ }^{18,19}$ In our study the single double-lumen cannula placed in a venous manner avoided this effect, not observing episodes of ischemia of lower extremities. On the other hand, as we commented previously, the iLA device in pumpless mode does not achieve sufficient blood oxygenation

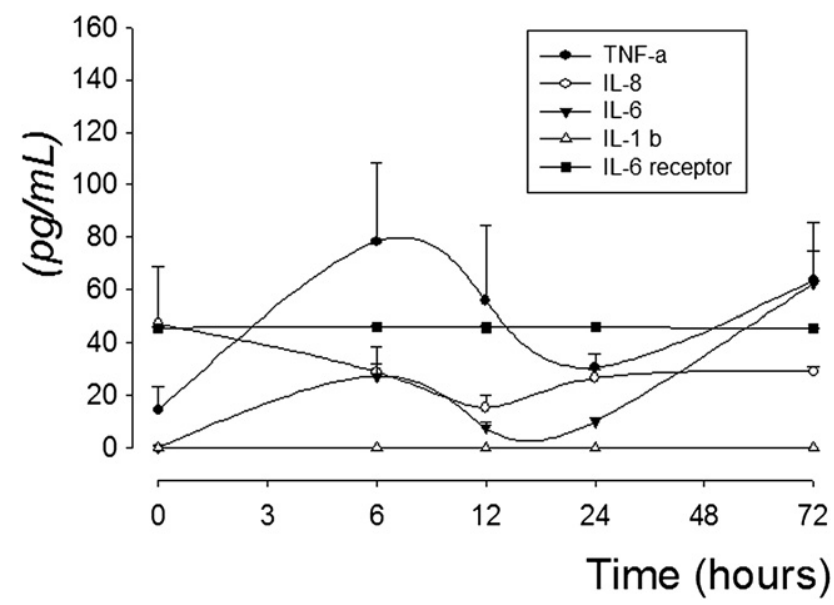

FIGURE 2. Correlation between mean plasma cytokine values and time. $T N F$, Tumor necrosis factor; $I L$, interleukin. 


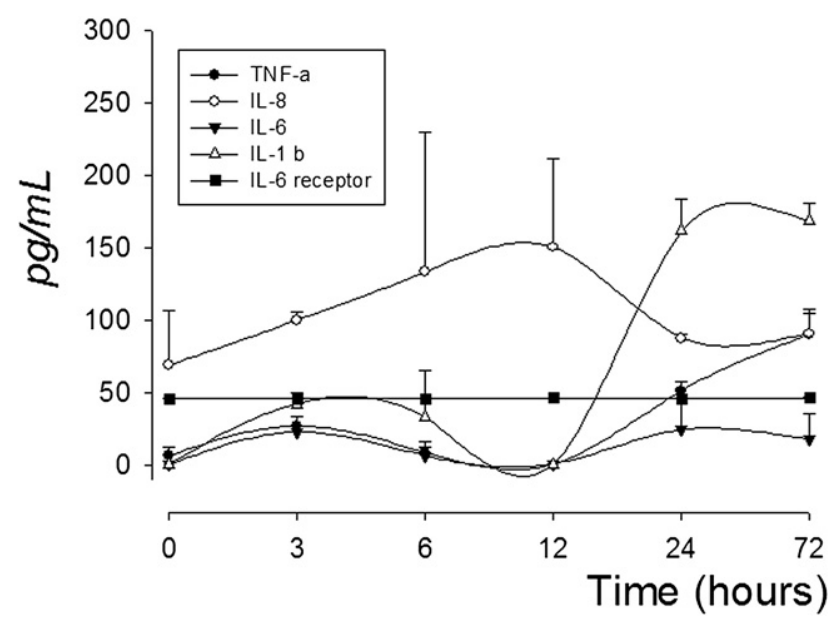

FIGURE 3. Correlation between mean lung cytokine values and time. $T N F$, Tumor necrosis factor; $I L$, interleukin.

because of limited blood flow ${ }^{6}$; a pump-driven circuit like the one we used allowed us to increase the blood flow and obtain an optimal oxygenation $\left(\mathrm{PaO}_{2}\right.$ of $\left.226.2 \pm 56.4\right)$ despite near-apneic ventilation and room air $\mathrm{FIO}_{2}$.

We used a single double-lumen cannula placed in the femoral-jugular veins where one lumen drains blood and one returns oxygenated blood. To place a unique cannula has different advantages. One is to avoid any vessel manipulation (eg, vascular lesion, bleeding focus, and problems with cannulation), and another is that it allows a shorter circuit. Because this second benefit maintained a physiological body temperature $\left(36.4^{\circ} \mathrm{C} \pm 0.3^{\circ} \mathrm{C}\right.$ ) over time (72 hours in our study), the circuit did not need a blood-holder line. Also, no pig required volume support or vasoactive drugs to maintain hemodynamic stability because of low blood loss inside the circuit (Table 1). The end of the cannula was placed through the femoral vein and was below the renal vein's takeoff, not hindering renal venous drainage without an effect on the function of this organ; the length of the cannula was enough to permit an appropriate blood circuit and gas exchange, and there were no differences between femoral (26F) and jugular (22F) vein cannulation. The only thing to highlight on the cannula prototype used is that it is difficult to place with Seldinger's technique because of its length, which makes it difficult to hinder the final leg of its introduction. We propose for future studies to change its structure, such as its distal end, to facilitate its sliding on the vessel.

The Levitronix CentriMag Blood Pump is a thirdgeneration blood pump with a magnetic bearing. This pump is based on the "bearingless motor" technology, which combines the drive, magnetic bearing, and rotor functions into a single unit. The motor generates the magnetic bearing force and torque necessary to produce the unidirectional flow. The absence of bearings and seals results in minimal friction or heat generation in the blood path and minimum blood cell damage. Another advantage of this pump is the absence of a blood pool, minimizing the cell trauma and coagulation alterations; it also does not require a blood heater.

In conclusion, the venous-venous, pump-driven, extracorporeal lung membrane, single double-lumen cannula system is an effective provider of total respiratory support over 72 hours in a healthy pig model without inducing hemodynamic, coagulatory, cellular, or inflammatory imbalances and can be placed either in the jugular or femoral veins. Patients with acute or chronic lung failure who present with severe hypoxemia, hemodynamic instability, or important arteriopathy and cannot benefit from the extracorporeal arteriovenous Novalung pumpless system could benefit from the investigated circuit.

\section{References}

1. The Acute Respiratory Distress Syndrome Network: ventilation with lower tidal volumes as compared with traditional tidal volumes for acute lung injury and the acute respiratory distress syndrome. $N$ Engl J Med. 2000;342:1301-8.

2. Conrad SA, Zwischenberger JB, Grier LR, Alpard SK, Bidani A. Total extracorporeal arteriovenous carbon dioxide removal in acute respiratory failure: a phase I clinical study. Intensive Care Med. 2001;27:1340-51.

3. Alpard SK, Zwischenberger JB, Tao W, Deyo DJ, Bidani A. Reduced ventilator pressure and improved $\mathrm{P} / \mathrm{F}$ ratio during percutaneous arteriovenous carbon dioxide removal for severe respiratory failure. Ann Surg. 1999;230:215-24.

4. Iglesias M, Martinez E, Badia JR, Macchiarini P. Extrapulmonary ventilation for unresponsive severe acute respiratory distress syndrome after pulmonary resection. Ann Thorac Surg. 2008;85:237-44.

5. Iglesias M, Jungebluth $\mathrm{P}$, Albado I, et al. Experimental safety and efficacy evaluation of an extracorporeal pumpless artificial lung in providing respiratory support through the axillary vessels. J Thorac Cardiovasc Surg. 2007;133: 339-45.

6. Fischer S, Simon AR, Welte T, et al. Bridge to lung transplantation with the novel pumpless interventional lung assist device NovaLung. J Thorac Cardiovasc Surg. 2006;131:719-23.

7. De Robertis F, Birks EJ, Rogers P, Dreyfus G, Pepper JR, Khaghani A. Clinical performance with the Levitronix Centrimag short-term ventricular assist device. J Heart Lung Transplant. 2006;25:181-6.

8. Kopp R, Dembinski R, Kuhlen R. Role of extracorporeal lung assist in the treatment of acute respiratory failure. Minerva Anestesiol. 2006;72:587-95.

9. Mols G, Loop T, Geiger K, Farthmann E, Benzing A. Extracorporeal membrane oxygenation: a ten-year experience. Am J Surg. 2000;180:144-54.

10. Hemmila MR, Rowe SA, Boules TN, et al. Extracorporeal life support for severe acute respiratory distress syndrome in adults. Ann Surg. 2004;240:595-607.

11. Alpard SK, Zwischenberger JB. Extracorporeal membrane oxygenation for severe respiratory failure. Chest Surg Clin North Am. 2002;12:355-78.

12. The Acute Respiratory Distress Syndrome Network. Ventilation with lower tidal volumes as compared with traditional tidal volumes for acute lung injury and the acute respiratory distress syndrome. $N$ Engl J Med. 2000;342:1301-8.

13. Reng M, Philipp A, Kaiser M, Pfeifer M, Gruene S, Schoelmerich J. Pumpless extracorporeal lung assist and adult respiratory distress syndrome. Lancet. 2000; 356:219-20.

14. Matthais G. New technologies for respiratory support. Perfusion. 2003;18:245-51.

15. Iglesias M, Martinez E, Badia JR, Macchiarini P. Extrapulmonary ventilation for unresponsive severe acute respiratory distress syndrome after pulmonary resection. Ann Thorac Surg. 2008;85:237-44.

16. Wang D, Lick SD, Campbell KM, et al. Development of ambulatory arteriovenous carbon dioxide removal (AVCO2): the downsized gas exchanger prototype for ambulation removes enough $\mathrm{CO} 2$ with lox blood resistance. ASAIO J. 2005;51:385-9.

17. Go T, Altmayer M, Richter M, Macchiarini P. Decompresssing manubriectomy under apneic oxygenation to release the median thoracic outlet compartment in Bechterex disease. J Thorac Cardiovasc Surg. 2003;126:867-9.

18. Müller T, Lubnow M, Philipp A, et al. Extracorporeal pumpless interventional lung assist in clinical practice: determinants of efficacy. Eur Respir J. 2009;33:551-8. 
19. Haley MJ, Fisher JC, Ruiz-Elizalde AR, et al. Percutaneous distal perfusion of the lower extremity after femoral cannulation for venoarterial extracorporeal membrane oxygenation in a small child. J Pediatr Surg. 2009;44:437-40.

\section{Discussion}

Dr Joseph B. Zwischenberger (Lexington, Ky). Paulo Macchiarini's laboratory is to be congratulated as one of a handful in the world that can do these long-term studies. What they have done is put together a system with the Novalung double-lumen catheter, a CentriMag pump, and a Novalung gas exchange device in which they used catheters in both the internal jugular vein and the femoral vein to accomplish total gas exchange with only 2 to $3 \mathrm{~L}$ of flow, and these studies lasted for 72 hours.

A double-lumen catheter has been available since the mid1980s, when we designed the first double-lumen catheter. It then became the standard of care for neonates, eventually going into children and adults. Recently, the Avalon company has developed the Elite catheter, which allows percutaneous double-lumen venous-venous gas exchange for total gas exchange.

Therefore what you have to ask yourself is this: What have they really done here? They have been able to put together what I would call a successful system. They have taken a gas exchange device, a pump, and a catheter; put it together in a component system; and developed a way of providing systemic anticoagulation. With that system, they are able to accomplish total gas exchange with minimum inflammatory mediator activation. Although they did not in this model, the setup does allow the potential for ambulation, which we consider the holy grail for a bridge to transplantation and for long-term respiratory support.

Therefore with that in mind, I have a few questions. First of all, how did you confirm catheter placement? With a double-lumen catheter, often location is critical in terms of achieving flow. Second, how long could you go without having to change out this system? Third, please comment on the potential for ambulation because many of us believe that ambulation is necessary to provide a bridge to transplantation or long-term recovery.
Dr Macchiarini (Barcelona, Spain). Thank you, Jay.

Concerning the first question, we check where it was placed and whether it was placed correctly with a chest radiograph. Usually the tip of this cannula comes just below the right renal vein. Therefore it is fine because it does not go in the right heart. This was confirmed as well at the end of the study through autopsies.

As for the third question about ambulatory issues, I think that this is a prototype. It is not something that we could immediately put into the clinical scenario. However, I could imagine that the jugular vein access is something that could be used. We would need, let's say, a huge pump because the electronics is something that you cannot move.

I do not remember the second question.

Dr Zwischenberger. How long could you go without a change out?

Dr Macchiarini. Well, we did it for 3 days. I think that given that we did not have requirements like vasoactive drugs or that we did not do blood transfusions and so forth, we can go for at least 1 week or more, and this is the beauty of this system, with a very low morbidity profile.

Dr Shaf Keshavjee (Toronto, Ontario, Canada). Paulo, how did you use the catheter when placing it femorally versus placing it centrally in terms of recirculation in terms of design? Did you just switch ports?

Dr Macchiarini (Barcelona, Spain). No, it probably did not show up in the slides, but we just randomly assigned one pig or the other to jugular or femoral vein access.

Dr Keshavjee. To clarify, I mean in terms of recirculation of oxygenated return with venous blood.

Dr Macchiarini. We evaluated the venous oxygenation to see whether this mixing would induce hypoxic vasoconstriction, and the values were greater than $80 \%$. Therefore this is another issue that we were able to avoid, and the fact is that a lot of holes are very close to the tip of the cannula, so the distance between the tip of the cannula and the pulmonary circulation is very short, and we did not have any influence on these oxygenation mixtures. 


\section{WORK PLANNING}

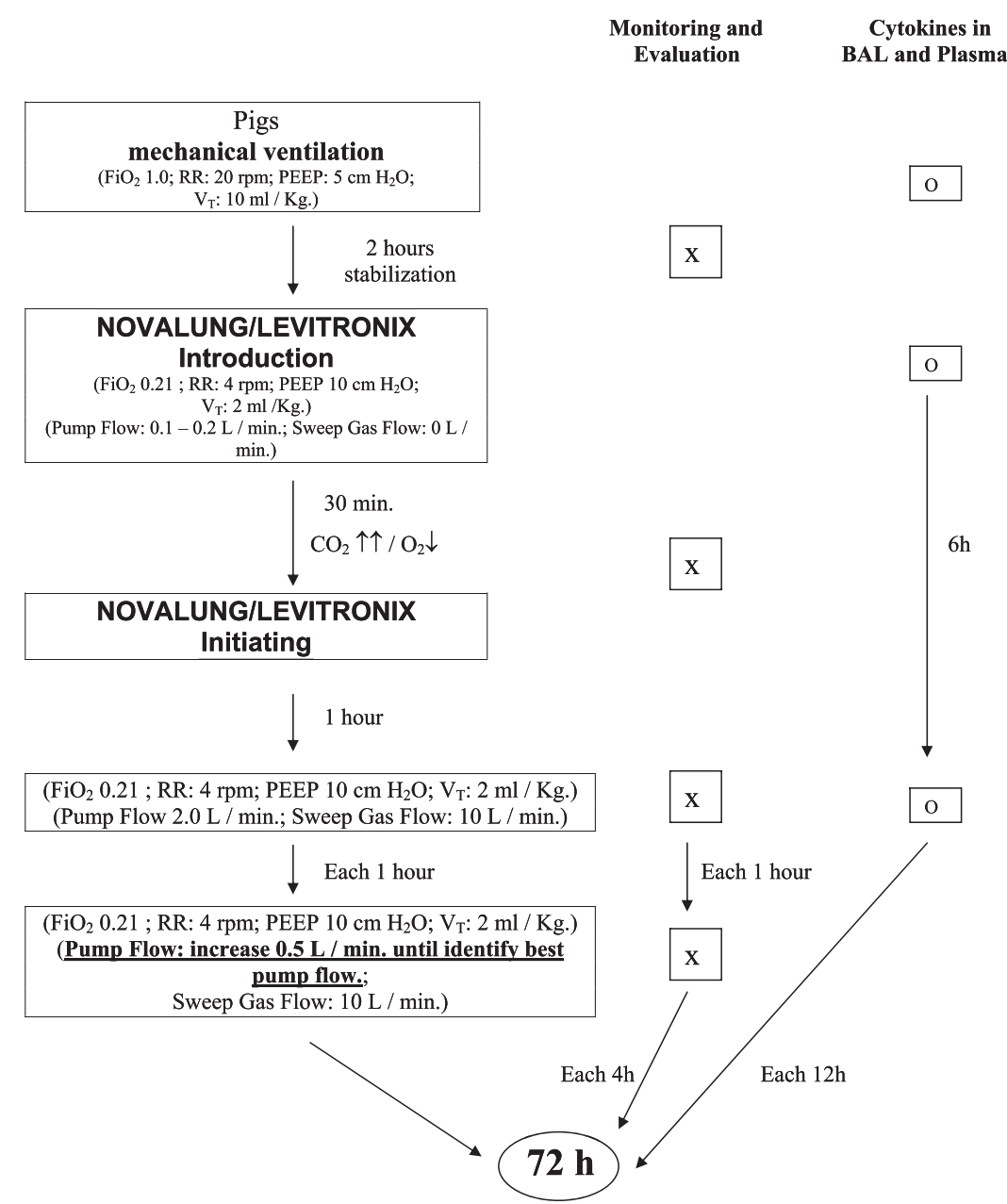

FIGURE E1. Work planning. $B A L$, Bronchoalveolar lavage; $\mathrm{Fio}_{2}$, fraction of inspired oxygen; $R R$, respiratory rate; $P E E P$, positive end-expiratory pressure; $V_{T}$, tidal volume. 


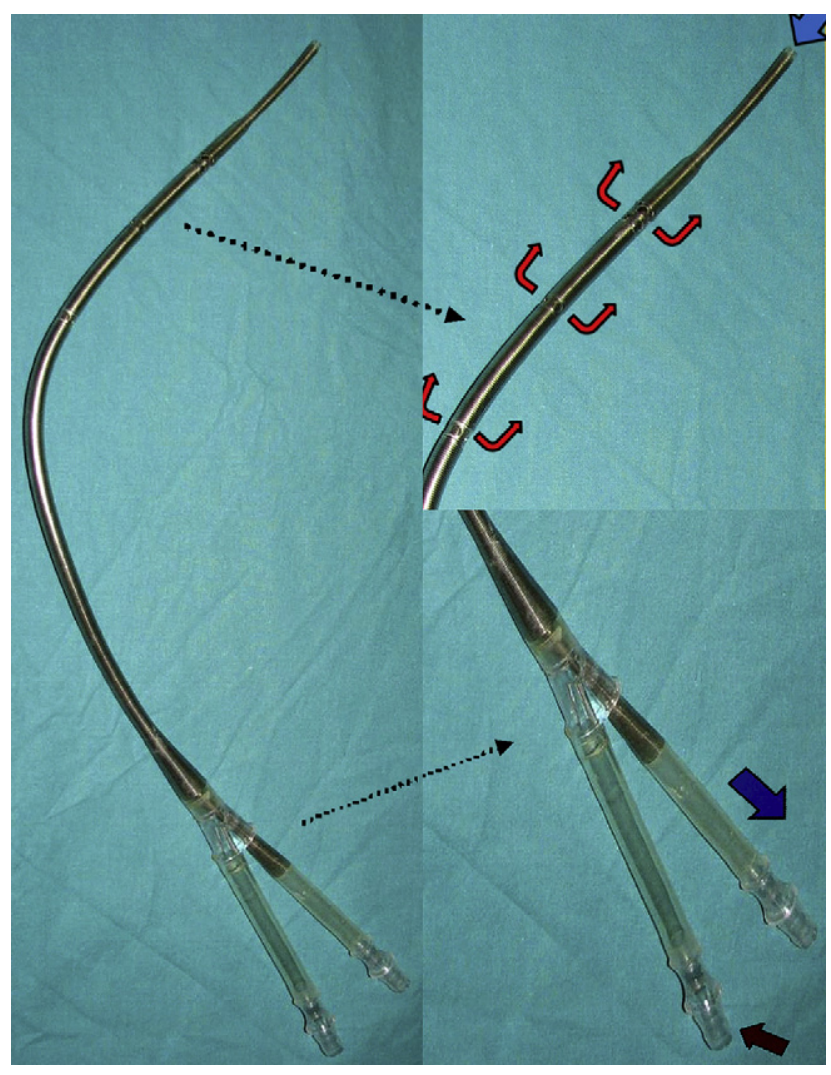

FIGURE E2. Photograph of the cannula with magnification of its distal and proximal parts. The type of blood flowing through the cannula is indicated by red (arterial) and blue (venous) arrows.

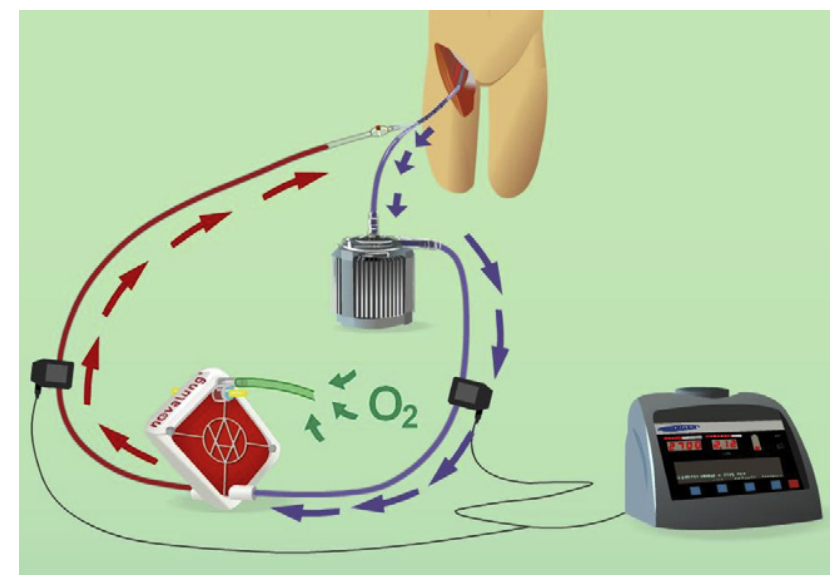

FIGURE E3. Schematic image illustrating the entire system function. The single double-lumen cannula is placed in the right femoral or jugular vein by using Seldinger's technique. It drains the venous blood through the pump to the Novalung gas exchange device and then flows back (oxygenated and normal levels of carbon dioxide) through the same cannula in the original vein. 